Original Research Article

\title{
Variation of hemodynamic response following induction and tracheal intubation: etomidate vs midazolam
}

\author{
Binod Pegu*, Deba Gopal Pathak, Suneeta Dutta, Bublee Khakhlary
}

Department of Anaesthesiology, Silchar Medical College,

Silchar, Assam, India

Received: 07 January 2017

Accepted: 07 February 2017

*Correspondence to:

Dr. Binod Pegu,

Email:

binodpegu10@gmail.com

Copyright: (C) the author(s), publisher and licensee Medip Academy. This is an openaccess article distributed under the terms of the Creative Commons Attribution NonCommercial License, which permits unrestricted noncommercial use, distribution, and reproduction in any medium, provided the original work is properly cited.

\begin{abstract}
Background: Induction and endotracheal intubation are invariably associated with certain cardiovascular changes during anaesthesia practice and can lead to sudden swings of blood pressure, arrhythmias, MI and cardiovascular collapse especially in geriatric and haemodynamically unstable patients. Therefore it is desirable to use a safer agent with fewer adverse effects to minimise these complications. Present prospective randomized study is designed to compare the haemodynamic alterations and various adverse effects following induction with etomidate and midazolam.

Methods: Hundred ASA I and II patients of age group 18-60 years scheduled for elective surgical procedure under general anesthesia were randomly divided into two groups of 50 each receiving etomidate $(0.3 \mathrm{mg} / \mathrm{kg})$ and midazolam $(0.15 \mathrm{mgk} / \mathrm{kg})$ as an induction agent. Vital parameters before and after induction and thereafter at specified time interval following laryngoscopy and intubation were recorded for comparison. Adverse effect viz. pain on injection, apnea and myoclonic activity were also carefully watched.

Results: Demographic variables in both the groups were comparable. Patients in both the groups showed little change in mean arterial pressure (MAP) and heart rate $(\mathrm{HR})$ from baseline value $(\mathrm{p}>0.05)$. Pain on injection and myoclonic activity were seen in etomidate group while delayed awakening was seen with Midazolam group.

Conclusions: This study concludes that both etomidate and midazolam provides haemodynamic stability but Midazolam can be preferred as an induction agent in view of fewer side effects.
\end{abstract}

Keywords: Etomidate, Endotracheal intubation, Haemodynemic stability, Midazolam

\section{INTRODUCTION}

Induction of anaesthesia in adults usually includes intravenous drug administration. Induction agents are drugs that, when given intravenously in an appropriate dose, cause a rapid loss of consciousness. They may be used for maintenance of anaesthesia, as sedatives at subanaesthetic doses, for longer procedures by intravenous infusion to provide conscious sedation during procedures undergoing in local anesthesia and in intensive care unit. ${ }^{1}$ None of the currently available induction agents is ideal. The knowledge and the availability of increasingly shorter acting drugs now allow the anaesthesia provider to administer not on basis of needs of the population but on the individual needs of the patient. However, hemodynamic variations like hypotension due to cardiovascular depression and hypertension due to stress response to laryngoscopy and intubation are very common following induction. $^{2}$

Etomidate, having a carboxylated imidazole ring that is critical for its anesthetic actions, which are mediated by specific $Y$-amino butyric acid type-A receptors in the central nervous system has a very high therapeutic index and is unique among the agents used for induction of anaesthesia. ${ }^{3}$ With a single bolus injection, even in patients in shock or who exhibit depressed left ventricular function, etomidate provides a stable hemodynamic with 
no effects on sympathetic nervous system as well as on the baroreceptor reflex regulatory system. ${ }^{4}$ Because of this hemodynamic stability etomidate has been often used as an induction agent of choice in the emergency room and the intensive care unit for rapid-sequence inductions and for induction of general anesthesia in the cardiac surgeries. However in critically ill patients, especially those in septic shock, adrenal insufficiency is a fairly common occurrence. ${ }^{5}$

Midazolam (MDZ) is a benzodiazepine agonist that has some advantages over other benzodiazepines as an induction agent. Being water soluble midazolam causes less venous irritation. It has a rapid onset of action and fast distribution with few cardiovascular or respiratory effects after intravenous (IV) injection which makes it a good choice for conscious sedation, induction and for maintenance of anesthesia. MDZ curtails the postoperative recall by providing anterograde amnesia, which has always been an unpleasant experience following anesthesia. ${ }^{6,7}$

\section{METHODS}

After obtaining approval from the institutional ethical committee clearance, a prospective, randomized, controlled and parallel group clinical study was conducted in 100 patients aged 18-60 years of both sexes belonging to ASA grade I and II undergoing elective non cardiac surgery requiring endotracheal intubation for maintenance of anaesthesia. A written informed consent was taken from all the patients individually.

Patients belonging to ASA III and above, patients with other co-morbid illness like diabetes, hypertension, respiratory disease, hepatic or renal derangements; history of seizure disorder, presence of primary and secondary steroid deficiency/on steroid medication patients on antipsychotic medication, history of allergy to the study drugs, anticipated difficult airway etc. were excluded from the study.

A detailed pre-anaesthetic evaluation including routine investigations was done on all patients and was explained about the anaesthesia technique.

All patients were given Tablet Alprazolam $0.5 \mathrm{mg}$, orally on the night before the operation and preoperative fasting for 8 hours were ensured before administering the general anaesthesia. On arrival at operation theatre, patients were attached with standard anesthesia monitoring including Electrocardiogram (ECG), Non-invasive blood pressure (NIBP), Pulse oximeter and baseline vital parameters were recorded.

An 18G intravenous (I.V.) cannula was secured and ringer lactate $10 \mathrm{~mL} / \mathrm{kg} / \mathrm{h}$ were started. Patients were randomly divided into 2 groups of 50 patients in each group and premedicated with Inj. Glycopyrrolate $0.2 \mathrm{mg}$, Ondansetron $4 \mathrm{mg}$ and Tramadol $1 \mathrm{mg} / \mathrm{kg}$ I.V.
- $\quad$ Group I = Induced with Inj. Midazolam (0.15 $\mathrm{mg} / \mathrm{kg}$ )

- Group II = Induced with Inj. Etomidate $(0.3$ $\mathrm{mg} / \mathrm{kg}$ )

Patients were intubated with appropriate size of ETT after 3 mins of intubating dose of vecuronium $(0.1 \mathrm{mg} / \mathrm{kg}$ i.v. $)$ and endotracheal tube was secured after confirming correct position and positive pressure ventilation was initiated. Anaesthesia was maintained with $66.6 \% \mathrm{~N}_{2} \mathrm{O}$ in O2, Sevoflurane $0.2-1 \%$ inj. Vecuronium top up doses whenever necessary. Residual neuromuscular blocked was reversed with inj. Neostigmine $(0.05 \mathrm{mg} / \mathrm{kg})$ and inj. Glycopyrrolate $(0.01 \mathrm{mg} / \mathrm{kg})$ I.V. and extubation was performed when respiration was adequate and patient was able to obey verbal commands.

\section{Haemodynamic parameters}

SBP, DBP MBP and HR were continuously monitored and recorded just before(T0) and after induction (T) followed by $1 \mathrm{~min}$ (T1), 3min (T3), $5 \mathrm{~min}$ (T5) and 10min (T10) after intubation. Adverse effects like Pain on injection, Myoclonic movements, Episode of apnea, ECG changes, if occurred were recorded.

\section{Statistical analysis}

The data were recorded on predesigned and pretested proforma. Demographic data, Heart Rate (HR), systolic $\mathrm{BP}$, diastolic BP and Mean arterial pressure (MAP) were tabulated as Mean and Standard deviation. Statistical significance was tested by one way ANNOVA for continuous variables and chi-square test for categorical variables. P-value of less than 0.05 was considered significant.

\section{RESULTS}

This study was conducted in an attempt to evaluate the effects of Midazolam and Etomidate when used as inducing agents by comparing certain parameters such aschange in blood pressure and heart rate following induction and intubation as well as side effects like pain on injection, myoclonic movements, apnea on induction etc.

Table 1: Demographic profile.

\begin{tabular}{|lclllc|}
\hline Group & No. & $\begin{array}{l}\text { Age } \\
\text { (years) }\end{array}$ & $\begin{array}{l}\text { Sex } \\
\text { M:F }\end{array}$ & $\begin{array}{l}\text { Weight } \\
(\mathrm{Kg})\end{array}$ & $\begin{array}{c}\text { ASA } \\
\text { I/II }\end{array}$ \\
\hline $\begin{array}{l}\text { Group 1 } \\
\text { (Etomidate) }\end{array}$ & 50 & $36.2 \pm 5.2$ & $28: 22$ & $59.4 \pm 3.1$ & $29 / 21$ \\
\hline $\begin{array}{l}\text { Group 2 } \\
\text { (Midazolam) }\end{array}$ & 50 & $34.6 \pm 6.4$ & $26: 24$ & $58.5 \pm 2.6$ & $26 / 24$ \\
\hline
\end{tabular}

Demographic characteristics of patients and pre induction values of the hemodynamic variables were comparable ( $\mathrm{p}$ $>0.05)$. 


\section{Hemodynamic variables}

Pre-Induction vitals (HR, SBP, DBP and MAP) were comparable in both groups with no statistically significant differences $(\mathrm{p}>0.05)$ (Table 2$)$. The changes in MAP and heart rate from baseline were more in midazolam group than etomidate group with maximum changes at 1 st post-intubation period but statistically no significant difference was found in between the groups at any point of time period (Figure 1 and Figure 2).

Table 2: Heart rate changes.

\begin{tabular}{|llll|}
\hline Time & Etomidate & Midazolam & P value \\
\hline T0 & $93.23 \pm 6.76$ & $91.15 \pm 4.15$ & $>0.05$ \\
\hline T & $90.38 \pm 7.92$ & $89.93 \pm 6.61$ & $>0.05$ \\
\hline T1 & $\begin{array}{l}102.75 \pm 5.8 \\
(10 . \% \text { rise })\end{array}$ & $\begin{array}{l}105.68 \pm 5.81 \\
(16.1 \% \text { rise })\end{array}$ & $>0.05$ \\
\hline T3 & $98.33 \pm 3.81$ & $101.25 \pm 5.18$ & $>0.05$ \\
\hline T5 & $95.20 \pm 6.20$ & $97.53 \pm 5.40$ & $>0.05$ \\
\hline T10 & $94.20 \pm 5.20$ & $96.53 \pm 6.40$ & $>0.05$ \\
\hline
\end{tabular}

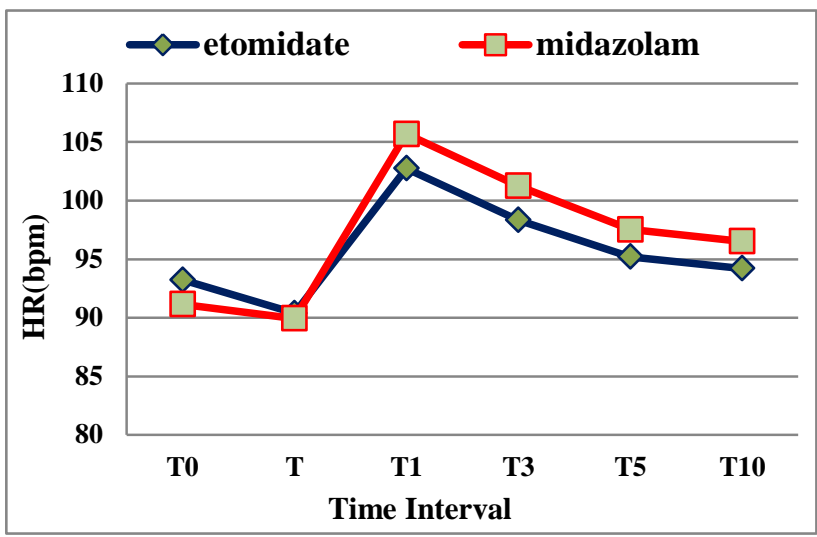

Figure 1: HR changes at different time intervals.

Increase in heart rate from baseline at induction is significantly high in midazolam group at 1st postintubation minute but ( $p>0.05)$, comparable to etomidate $(\mathrm{p}>0.05)$.

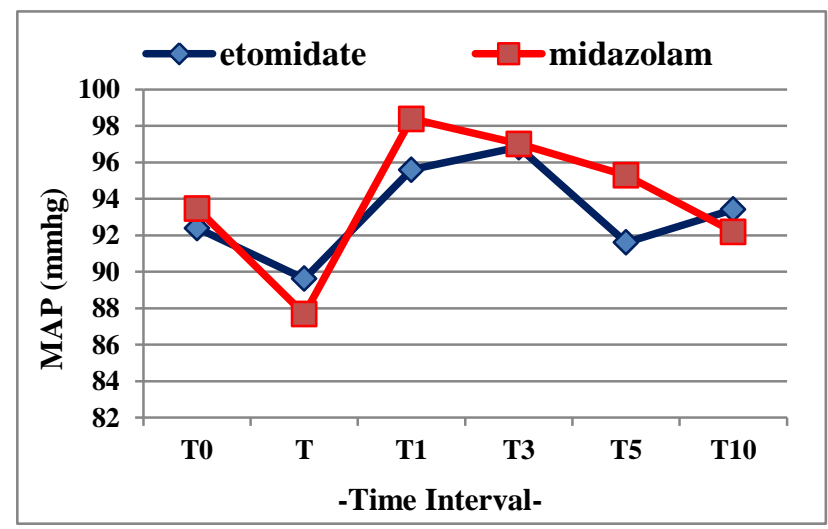

Figure 2: MAP at different time intervals.
Table 3: MAP (mmhg) changes.

\begin{tabular}{|lll|l|}
\hline Time & Etomidate & Midazolam & P-value \\
\hline T0 & $92.4 \pm 8.37$ & $93.48 \pm 9.38$ & $>0.05$ \\
\hline T & $\begin{array}{l}89.63 \pm 6.08 \\
(3.11 \% \text { fall })\end{array}$ & $\begin{array}{l}87.68 \pm 7.14 \\
(6.61 \% \text { fall })\end{array}$ & $>0.05$ \\
\hline T1 & $95.60 \pm 11.22$ & $98.39 \pm 5.17$ & $>0.05$ \\
\hline T3 & $96.84 \pm 9.04$ & $97.02 \pm 6.52$ & $>0.05$ \\
\hline T5 & $91.62 \pm 7.98$ & $95.30 \pm 5.54$ & $>0.05$ \\
\hline T10 & $93.42 \pm 6.32$ & $92.20 \pm 6.34$ & $>0.05$ \\
\hline
\end{tabular}

Both the groups showed no significant changes from baseline during the post induction period s. MAP were comparable in between the groups ( $\mathrm{p}>0.05)$.

\section{Adverse effects}

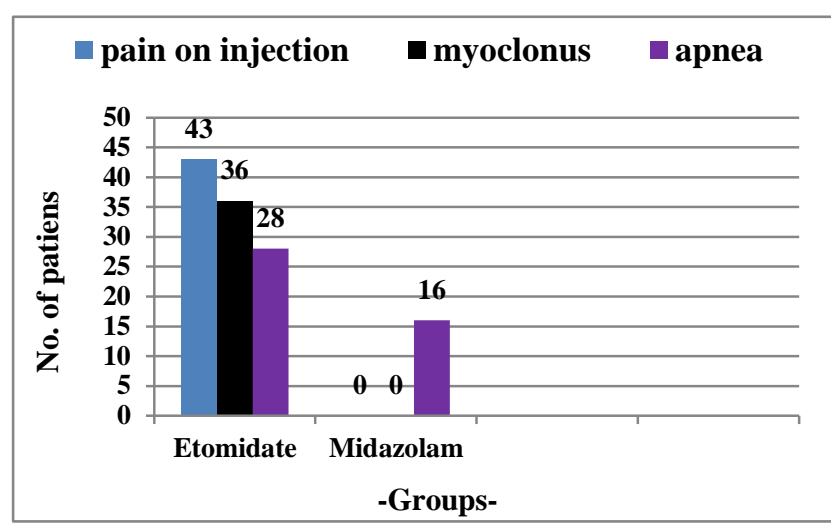

Figure 3: Adverse effects in both the groups.

\section{DISCUSSION}

Induction of anaesthesia is often associated with mild to moderate fluctuations of blood pressure heart rate which have deleterious effects on maintenance of circulation to vital organs in patients of coronary artery disease, valvular stenosis, uncontrolled hypertension and shock. None of the currently available intravenous anaesthetics are ideal as an induction agent. An ideal induction agent would be one that has rapid onset and offset, is easy to administer, and is devoid of clinically significant side effects. Several studies have been performed in order to find better anesthetic agents with least hemodynamic effects. $^{1,5}$

That etomidate has undoubtly superior cardiovascular stability as it is devoid of action on sympathetic nervous system. Etomidate, a carboxylated imidazole, is a potent, short-acting hypnotic, structurally unrelated to any other IV anesthetic having faster onset of action of 3-5 min, with a peak effect of 1 minute and duration of 3-5 minutes. ${ }^{8,9}$ It has been widely used as induction agent in patients with cardiovascular and pulmonary disease because of its minimal impact on cardiorespiratory function. $^{10}$ 
Daskaya et al reported that anesthesia induction with etomidate can be safely applied on hypertensive patients and does not result in hemodynamic instability neither in normotensive nor in hypertensive patients. In the normotensive group the reductions in MAP were around 3-5 $\mathrm{mmHg}$ average (not more than $10 \%$ of the preinduction values). ${ }^{11}$ Zhang et al also reported a reduction of average of $4 \mathrm{mmHg}$ in mean blood pressures in patients receiving etomidate. ${ }^{12}$

The role of etomidate is not restricted to normotensive patients only for its hemodynamic stability factor. Although etomidate can cause adrenal insufficiency in sepsis and critically ill patients in postoperative period, it provides less cardiovascular depression and minimize the use of vasopressor agents in these patients. ${ }^{13,14}$ Although etomidate has been widely used for its hemodynamic stability in certain settings, it is not devoid of side effects. P.J. Heath et al. observed spontaneous movement in $30 \%$, muscle twitch $40 \%$, tremor $50 \%$, pain on injection $45 \%$ and postoperative restlessness $35 \%$. $^{15}$

In critically ill patients, especially those in septic shock, adrenal insufficiency is a fairly common occurrence which is likely to have significant clinical ramifications as such patients often have a minimal physiologic reserve and may develop hemodynamic perturbations because of suppression of the adrenal axis. 4

Midazolam, a water-soluble benzodiazepine has two important advantages over other benzodiazepines: a short duration of action and absence of vascular irritation when administered intrvenously. ${ }^{16}$

W. HESS et al reported that Midazolam can be used as a valuable alternative to conventional induction agents in cardiac surgical patients without adverse effects on the cardiovascular system. ${ }^{17}$

The results we obtained from our study revealed no significant differences in the efficacies of the two drugs and neither caused major alterations in the haemodynamic variables. However, hypotension after induction was observed with Midazolam in few cases which may possibly be due to reduction of sympathetic activity causing vasodilatation and/or interference with the transmembrane influx of $\mathrm{Ca}^{2+}$ and its enhancement of NO synthesis from endothelial vascular smooth muscles. ${ }^{17,18}$

Pain on injection and myoclonus were observed only with Etomidate. Miner et al also concluded high incidence of myoclonus (20\%) with Etomidate. ${ }^{19}$ Although Etomidate can cause adrenal insufficiency in the patients in postoperative period, clinical consequence of that is still unclear over its advantage to prevent hypotension at induction. $^{20}$

Midazolam has several advantages as an induction agent. Since critically ill patients have a very small respiratory and ventilatory reserve, the rapid and short duration of action of midazolam favours its use in such cases. ${ }^{21}$ The literatures have reported that midazolam directly relaxes the muscles of the airway by enhancement of NO synthesis from endothelial vascular smooth muscles. Muscle relaxation property of midazolam presents a clear advantage providing optimum conditions for endotracheal intubation. $^{22}$ As an induction agent midazolam does not cause vomiting. It does not have a peripheral vascular irritant effect; hence no pain on injection like other commonly used agents. Midazolam can be used as an alternative induction in case sepsis. ${ }^{23}$

\section{CONCLUSION}

In conclusion, we unequivocally state that both Midazolam and Etomidate provide hemodynamic stability in normotensives and can be safely used as induction agents. However, preferring one drug over the other depends upon individual discretion. In our setting we would like to prefer Midazolam due to its added advantage of cost effectiveness and lack of side effects like myoclonus, pain on injection, adrenal suppression etc. particularly in patients prone to hemodynamic fluctuation at induction like uncontrolled hypertension, sepsis, critically ill. To arrive at more conclusive results, preferably multicentre studies involving large numbers of cases will be necessary.

Funding: No funding sources

Conflict of interest: None declared

Ethical approval: The study was approved by the Institutional Ethics Committee

\section{REFERENCES}

1. Aggarwal S. A comparative study between propofol and etomidate in patients under general anesthesia. Rev Bras Anestesiol; 2015.

2. Forbes AM, Dally FG. Acute hypertension during induction of anaesthesia and endotracheal intubation in normotensive man. Br J Anaesth. 1970;42:618-24.

3. Forman SA. Clinical and molecular pharmacology of etomidate. Anesthesiology. 2011;114:695-707.

4. Johnson KB, Egan TD, Layman J. The influence of hemorrhagic shock on etomidate: A pharmacokinetic and pharmacodynamic analysis. Anesthesiology. 2004;101:657-9.

5. Anita K. Malhotra, Con. Etomidate- The Ideal Induction Agent for a Cardiac Anesthetic? Journal of Cardiothoracic and Vascular Anesthesia. 2012;27(1):178-9.

6. Forster A, Gardaz JP, Suter PM, Gemperle M. IV Midazolam as an induction agent for anesthesia: a study in volunteers. Br J Anesth. 1980;52(9):907-11.

7. Twersky RS, Hartung J, Berger BJ, McClain J, Beaton C. Midazolam enhances anterograde amnesia but not retrograde amnesia in pediatric patients. Anesthesiology. 1993;78(1):51-5. 
8. Doenicke A. Etomidate. A new intravenous hypnotic. Acta Anaesthesiol Belg. 1974;25:307-15.

9. Wolfson AB. Harwood-Nuss' Clinical Practice of Emer $\neg$ gency Medicine, 4th Ed; Portland; Lippincott Williams \& Wilins; 2005:1150-1153.

10. Gooding JM, Weng JT, Smith RA. Cardiovascular and pulmonary response following etomidate induction of anesthesia in patients with demonstrated cardiac disease. Anesth Analg. 1979;058:40-1.

11. Daşkaya H, Uzman S, Çiftçi T, Gün Y, Toptaş M, Demir $\mathrm{M}$, et al. Comparison of the hemodynamic effects of etomidate between hypertensive and normotensive patients; 2015.

12. Zhang GH, Sun L. Peri-intubation hemodynamic changes during low dose fentanyl, remifentanil and sufentanil combined with etomidate for anesthetic induction. Chin Med J. 2009;122:2330-4.

13. Ray DC, McKeown DW. Etomidate for critically ill patients. Pro:yes we can use it. Eur J Anaesthesiol. 2012;29:506-22.

14. Ray DC, Hay AW, McKeown DW. Induction drug and outcome ofpatients admitted to the intensive care unit after emergencylaparotomy. Eur J Anaesthesiol. 2010;27:481-5.

15. Heath PJ, Kennedy DJ, Ogg TW, Dunling C, Gilks WR. Which intravenous induction agent for day surgery? A comparison of propofol, thiopentone, methohexitone and etomidate. 1988 May;43(5):3658.

16. Forster JP, Gardaz PM, Sitter, Gemperle M, Anaesth Br. J. Midazolam as an induction agent for anaesthesia: a study in volunteers. 1980;52:907.
17. Schulte-Sasse U, Hess W, Tarnow J. Haemodynamic responses to induction of anaesthesia using midazolam in cardiac surgical patients. Br. J. Anaath. 1982;54:1053.

18. Hussain ZK, Saberi H, Bitaraf MA. The dilemma of hemodynamic instability during induction of anesthesia: can midazolam serve as a suitable substitute for thiopentone? Tehran University of Medical Sciences, Tehran 14197,1. R. Jran. 1999;17(2):115-18.

19. Miner JR, Danahy M, Moch A. Randomized clinical trial of Etomidate versus propofol for procedural sedation in the emergency department. Ann Emerg Med. 2007;49:15-22.

20. Nyman Y, von Hofsten K, Ritzmo C. Effect of a small priming dose on myoclonic movements after intravenous anaesthesia induction with EtomidateLipuro in children. Br J Anaesth. 2011;107:225-8.

21. Nordt S, Clark R. Midazolam: A review of therapeutic uses and toxicity. J Emerg Med. 1997; 15(3):357-65.

22. Reves, Fragen J, Vinik HR. Midazolam: Pharmacology and uses. Anesthesiology. 1985;62:310-24.

23. Induction Agents for Endotracheal Intubation in Severe Sepsis and Septic Shock. Marie Mullen, Department of Emergency Medicine, University of Massachusetts, Worcester, MA, USA; 2012.

Cite this article as: Pegu B, Pathak DG, Dutta S, Khakhlary B. Variation of hemodynamic response following induction and tracheal intubation: etomidate vs midazolam. Int J Basic Clin Pharmacol 2017;6:597-601. 